\title{
UMA EXPERIÊNCIA DE ESTÁGIO NA GESTÃO ESCOLAR: FORMAÇÃO CONTINUADA COM PROFESSORES DA EDUCAÇÃO INFANTIL \\ http://dx.doi.org/10.5902/2318133838879
}

\author{
Nathany Morais de Souza ${ }^{1}$ \\ Micarla Silva de Azevedo ${ }^{2}$ \\ Flávia Alessandra Pereira Galdino ${ }^{3}$ \\ Nazineide Brito ${ }^{4}$
}

\begin{abstract}
Resumo
O presente estudo é resultado de uma experiência de estágio supervisionado do curso de Pedagogia da UFRN/Ceres/Caicó, desenvolvido na gestão de uma instituição de educação infantil. Buscou-se investigar o processo de formação continuada como espaço de reflexão e transformação da prática docente e intervir, pela da promoção de uma formação continuada, com as professoras da referida instituição, levando-se em consideração o elo entre coordenação e corpo docente. Assim, teve como princípios metodológicos a pesquisa in lócus por meio de observações e o uso de ferramentas de cunho qualitativo como a aplicação de questionários. Notou-se que a formação continuada e a organização do trabalho docente contribuem de forma indubitável para a melhoria pessoal e profissional do educador.

Palavras-chave: formação continuada; prática docente; docente.
\end{abstract}

\section{AN EXPERIENCE OF STAGE IN SCHOOL MANAGEMENT: CONTINUED TRAINING WITH TEACHERS OF CHILD EDUCATION}

\begin{abstract}
The present study is the result of a supervised internship experience of the UFRN/Ceres/Caicó Pedagogy course developed in the management of a child education institution. Thus, it sought to investigate the process of continuous training as a space for reflection and transformation of teaching practice and intervene through the promotion of continuing education with teachers of the institution, taking into account the link between coordination and faculty. Thus, the methodological principles were the in locus research through observations and the use of qualitative tools such as the application of questionnaires. In this way, continuing education and the organization of teaching work undoubtedly contribute to the personal and professional improvement of the educator.
\end{abstract}

Key-words: continuing education; teaching practice; teacher.

\footnotetext{
${ }^{1}$ Universidade Federal do Rio Grande do Norte, Brasil. E-mail: nathany.morais@hotmail.com.

2 Universidade Federal do Rio Grande do Norte, Brasil. E-mail: silvamicarla14@gmail.com.

3 Universidade Federal do Rio Grande do Norte, Brasil. E-mail: flaviagermanotta@gmail.com.

4 Universidade Federal do Rio Grande do Norte, Brasil. E-mail: nazibrito@gmail.com. 


\section{Introdução}

esde os primórdios da civilização a educação compõe parte estrutural do funcionamento da sociedade, seja por meio da educação informal ou pelo posterior ensino nas escolas. No entanto, no século 21 tornou-se possível ponderar que diversas discussões acerca dessa área ainda se fazem necessárias, dentre estas pode-se destacar a formação continuada e a organização do trabalho docente.

Sendo assim, ao considerar que a educação infantil é um dos pilares da escolarização básica no Brasil, torna-se profícuo um estudo a partir desse prisma. Posto isto, o presente trabalho foi desenvolvido a partir de um estágio na gestão da educação infantil e teve como objetivo central investigar o processo de formação continuada como extensão e reflexão da prática docente dentro da Creche Municipal Dona Oscarina de Oliveira Torres, localizada no município de Caicó/RN. Ademais, também buscou-se questionar de que forma as práticas docentes articulam, confrontam ou mesmo esclarecem os saberes teóricos na organização do trabalho escolar. Isto acrescido de uma formação continuada de atributo motivacional da prática docente.

No que diz respeito a relevância do presente trabalho são várias as razões que justificam o desenvolvimento da sua elaboração, dentre estas: a pertinência do trabalho articulado entre gestão e corpo docente, a prática do educador enquanto formador de pensadores críticos e autônomos desde a educação infantil e a indissociabilidade entre teoria e prática. Posto isso, pode-se afirmar que os elementos quando em conjunto com o trabalho do coordenador, dos professores e dos demais profissionais da escola possibilitam que as crianças desenvolvam uma construção do conhecimento sendo, portanto, capazes de criar, pensar, dialogar e exercer seus direitos e deveres.

Assim, a formação continuada se faz imprescindível para o desenvolvimento da vida profissional do professor ativo, pois por meio dela é possível pôr-se em contato com a atual dinâmica social refletida no contexto da instituição escolar e ainda possibilita o crescimento teórico-prático. Para tal, o estudo parte da caracterização do lócus de pesquisa e da observação da dinâmica institucional e dos professores para, por fim, mostrar a execução da formação continuada proporcionada pelas estagiárias junto à coordenação pedagógica da escola e em parceria com a UFRN/Ceres/Caicó, trazendo, portanto, a experiência de conhecer as instalações e a dinâmica presente no Núcleo de Educação da Infância de modo a despertar o caráter motivacional da prática docente.

\section{Percurso metodológico}

A metodologia utilizada no presente estudo possui caráter qualitativo, consistindo em um perfil exploratório, ocasionando uma observação do campo de pesquisa e também da utilização de um diário de campo, no qual foram registrados aspectos e comportamentos entendidos como essências, no que consiste a elaboração deste trabalho. Ademais, valeu-se de uma abordagem de análise bibliográfica e documental e a utilização de instrumentos para coleta de dados como diálogos e questionários.

O caminho teórico-metodológico trilhado também teve como abordagem a revisão literária com autores que tratam da temática abordada, na qual perpassa pela formação continuada em alicerce com a coordenação pedagógica. Logo, foram mobilizados autores como Imbernón (2010), Silva; Oliveira (2014) e ainda Libâneo; Oliveira; Toshi (2013), os quais trazem contribuições significativas no que se refere a formação continuada, ao 
destacarem inúmeros aspectos dessa formação e sua relação para a construção profissional e pessoal do professor. Além disso, revisou-se legislações e documentos primordiais para entender o contexto da educação infantil, tais como a Base Nacional Comum Curricular, a Lei de Diretrizes e Bases da Educação Nacional, Estatuto da Criança e do Adolescente, dentre outros.

O referido estudo iniciou-se a partir de uma observação das estruturas da escola com registro em diário de campo e, posteriormente, foram aplicados questionários e houveram reuniões dialogadas para saber como estavam situadas as práticas docentes. Diagnosticou-se algumas carências que poderiam ser superadas pelo processo de formação continuada e que refletiam de forma consequente nas práticas das professoras, evidenciando uma necessidade voltada ao interesse da criança. Dessa forma, algumas intervenções foram realizadas com o objetivo de possibilitar uma ampliação das práticas pedagógicas.

\section{A formação continuada no contexto da prática docente}

Ao longo do tempo a formação continuada ganhou um enfoque cada vez maior, haja vista que, com a Lei de Diretrizes e Bases da Educação Nacional os sistemas de ensino tiveram que voltar-se para o público docente tal como enfatiza o art. 67ํㅡㄹ inciso I, a fim de assegurar-Ihes o aperfeiçoamento profissional continuado, inclusive com licenciamento periódico remunerado para esse fim. Tal demanda pela formação continuada deve-se aos novos desafios da escola, junto com o modelo social vigente e os objetivos educacionais que sempre se renovam e requerem dos docentes o alcance de metas que estão continuamente sendo postas.

O Ministério da Educação, pela Rede Nacional de Formação Continuada de Professores, criada em 2004, teve como objetivo contribuir para a melhoria da formação dos professores e alunos. O público-alvo prioritário da rede são professores de educação básica dos sistemas públicos de educação. Desse modo, a formação continuada de professores se apresenta como imprescindível no que diz respeito a melhoria profissional e, consequentemente, a contribuição para os processos de ensino e aprendizagem dos alunos. Segundo Silva; Oliveira (2014), a formação continuada é favorável no contexto profissional pois

a formação continuada de professores é importante, pois amplia o conhecimento, leva a reflexão, a solução de problemas, mantém o professor atualizado, comprometido, aprende e ensina, leva a autoavaliação fazendo com que se sinta parte de um contexto onde o levará a formar cidadãos visando um futuro. (Silva; Oliveira, 2014, p. 75)

Nesse contexto, entende-se que a formação continuada é necessária para que se desenvolva o diálogo, a parceria entre professores, a inovação e trocas de experiências, ao mesmo tempo em que se coloca a escola como local de aprendizagem. Logo, pensar na melhoria profissional é também pensar no engrandecimento pessoal e subjetivo, adquirindo competências e habilidades que a formação inicial sozinha não consegue suprir.

Ademais, ao trazer para a discussão a temática da formação continuada é possível associá-la diretamente com a prática docente, de modo que esta é construída ao longo de toda trajetória acadêmica e profissional do professor. À vista disso, quando acrescida de 
formação continuada, a prática docente acaba sendo alvo da amplificação de novos aspectos, dinâmicas, teorias que perpassam por uma identidade docente que está sempre em processo de transfiguração:

A formação continuada de professores passa pela condição de que estes vão assumindo uma identidade docente, o que supõe a assunção do fato de serem sujeitos da formação, e não objetos dela, como meros instrumentos maleáveis e manipuláveis nas mãos de outros. (Imbernón, 2010, p. 11)

Diante disso, o professor detém da capacidade de reconstruir sempre sua prática e para isso são necessárias mudanças em seu campo pessoal e profissional. Nessa perspectiva, o desenvolvimento profissional seria o ponto principal da formação do professor e que acaba se correlacionando com o desenvolvimento pessoal e organizacional. Sendo que o desenvolvimento pessoal requer do docente uma reflexão acerca da sua prática, reconstrução de sua identidade pessoal e dentre outros investimentos. Já no quesito organizacional demandaria uma organização coletiva e pessoal no que se refere a escola. (Libâneo; Oliveira; Toshi, 2013).

Portanto, a formação continuada vai além de um treinamento de profissionais, desse modo, perpassa o campo profissional, pessoal e de identidade que se interligam à prática docente. Outrossim, é que o foco da formação continuada justifica-se pelo contexto e pelas demandas sociais, históricas, culturais que refletem dialeticamente dentro da instituição escolar e dentro da comunidade.

\section{Apresentação do lócus e funcionamento da escola}

A Creche Municipal Dona Oscarina de Oliveira Torres constitui-se como Centro Municipal de Educação Infantil - Cemei - e atende crianças de 0 a 5 anos de acordo com os respectivos níveis I, II, III, IV ou V. Além disso, seu funcionamento é em tempo integral, das $7 \mathrm{~h} 30 \mathrm{~min}$ às $17 \mathrm{~h} 30 \mathrm{~min}$. As instalações da creche foram idealizadas pelo Programa Nacional de Reestruturação e Aquisição de Equipamentos para a Rede Escolar Pública de Educação Infantil - Proinfância -, instituído pela resolução n. 6, de 24 de abril de 2007, que, por sua vez, visa a garantir o acesso de crianças a creches e escolas dentro de uma infraestrutura adequada.

Ao aprofundar-se no quesito da infraestrutura, conclui-se que a mesma foi muito bem pensada para cada setor de organização. As salas de aulas têm janelões de vidro que dão acesso ao solário de cada sala, oportunizando uma boa ventilação e iluminação natural, garantindo conforto ambiental dos seus usuários e qualidade sanitária do ambiente. Estes elementos estão em concordância com os Parâmetros básicos de infraestrutura para instituições de educação infantil (2006), pois é perceptível que há uma relação harmoniosa que garante o conforto ambiental para as crianças e profissionais.

No que se diz respeito ao financiamento da escola, a mesma fica por responsabilidade do Programa Dinheiro Direto na Escola - PPDE -, que se caracteriza por prestar assistência financeira às escolas da educação básica. O perfil dos alunos da instituição, em termos socioeconômicos, é bem diversificado e contempla crianças de famílias mais carentes, até crianças de famílias com um bom poder aquisitivo. 
O projeto político-pedagógico da escola encontra-se em processo de elaboração. Diante disso, a equipe gestora está empenhada nessa elaboração e afirma que um dos pontos importantes do projeto, tendo em vista o processo de andamento do que já foi realizado, é que o documento não está sendo construído apenas por parte da gestão da escola.

Assim, a elaboração do projeto político-pedagógico com a participação da comunidade escolar é importante, pois vai ao encontro do que enfatiza a Lei de Diretrizes e Bases da Educação Nacional (BRASIL, 1996), ao afirmar que para uma gestão de fato democrática, torna-se imprescindível que haja a participação dos profissionais e da comunidade independente da modalidade que se está trabalhando. Posto isso, torna-se possível afirmar que tal contexto influencia também na formação continuada e na organização do trabalho docente, haja vista que, a educação não está desvinculada do contexto macro que a sociedade ou mesmo a instituição se encontra.

\section{Observação da dinâmica institucional}

Para o conhecimento dos âmbitos administrativo e docente da Creche Municipal Dona Oscarina de Oliveira Torres foi realizado um momento de observação que ocorreu no período de quatro dias. Foi realizado um levantamento de dados das documentações, tais como o calendário escolar, plano de aula, projetos existentes na escola. No tocante ao calendário anual foi possível encontrar as datas das reuniões de planejamento mensal, bimestral ou semestral programados com participação ativa e obrigatória de todo o corpo docente e setor coordenativo da referida instituição.

Nesse contexto, discutiu-se também sobre 0 andamento do projeto políticopedagógico da escola, que ainda não foi finalizado, mas que já conta com a participação dos alunos e também com a colaboração dos pais: estes últimos deram sua contribuição por um questionário que a escola elaborou para que eles pudessem expor suas opiniões a respeito dos processos de ensino e aprendizagem dos seus filhos. Assim, busca-se engajar uma afetuosa parceria entre família e creche.

Por conseguinte, destinou-se à observação específica em sala de aula com a finalidade de conhecer mais da prática do professor em seu momento de efetivação dos conhecimentos adquiridos ao longo de sua formação profissional. $O$ grupo de pesquisadoras ficou subdivido e participaram do momento da roda de conversa em três turmas diferentes, sendo elas os níveis III - turmas A e B - e V, podendo entrar em contato com a rotina estabelecida por cada docente atuante.

Ao inferir os resultados das observações em salas de aula, constata-se que a instituição mantém um padrão pedagógico democrático, enriquecendo o pensar e a subjetividade de cada criança, assim como as mais diversas relações que o ser humano precisa estabelecer em seu processo de avanço educacional. Além disso, observou-se também que por mais que haja carências no processo de formação continuada, as docentes trabalham a contação de histórias e a partir disso relacionam com o cotidiano da criança, abrindo espaço para que elas possam refletir acerca dos seus conflitos internos, pois como bem afirma Bruno Bettelheim (2002): 
A integração interna não é algo que seja adquirido de uma vez por todas: é uma tarefa que nos confronta durante toda a vida, embora em forma e graus diferentes. Os contos de fadas não apresentam tal integração como um esforço duradouro; seria muito desencorajador para a criança, que acha difícil conseguir até mesmo uma integração temporária de suas ambivalências. Em vez disso, cada conto profeta no seu final feliz a integração de algum conflito interno. Dado que existem inúmeros contos de fadas, cada um apresentando uma forma diferente de um conflito básico como tema, em conjunto estas estórias demonstram que na vida encontramos muitos conflitos que devemos dominar, cada um de uma vez. (p. 97)

À vista disso, tem-se a oportunidade de discutir sobre a proposta de intervenção pensada pelas pesquisadoras. A priori, de acordo com o que foi analisado durante a semana, o grupo pensou em realizar uma ação colaborativa, procurando unificar uma parceria com os pais, a gestão, os alunos e a universidade. Tal proposta seria de uma formação continuada com as professoras, promovendo um olhar a partir das carências observadas para que houvesse um avanço quanto ao seu desempenho. Por este motivo, foi levantada uma sugestão de conduzir o grupo de professoras a uma atividade de campo, com destino ao Núcleo de Educação da Infância, na UFRN-campus central em Natal/RN, almejando um interesse pela prática vigente na instituição, sendo proposto uma reflexão sobre a metodologia apresentada.

Desta maneira, diante do que foi observado, foi possível estabelecer um encaminhamento mais consistente no que se destina à ação de intervenção. Sendo possível verificar que o objetivo desse primeiro momento foi alcançado ao constatar-se um pouco das experiências e vivências, que compõem uma instituição de Educação Infantil juntamente com o reconhecimento das demandas da referida escola.

\section{Um projeto de intervenção sob o olhar da formação continuada}

Levando-se em consideração o pensamento de Orsolon (2001), no que diz respeito ao processo de formação continuada, torna-se possível afirmar que a reflexão e a pesquisa quando incluídas na prática pedagógica, possibilitam o surgimento de questões relacionadas à percepção do docente e ao meio no qual está inserido. Sendo assim, mesmo apresentando muitos pontos relevantes na estrutura e no funcionamento da Instituição, tornou-se possível identificar a necessidade de um aprofundamento na formação continuada na prática das docentes.

Nesse contexto, objetivou-se instigar tais professoras a uma reflexão e oportunizar que as mesmas vivenciassem uma experiência pautada na indissociabilidade teoriaprática, contribuindo assim para se repensar, definir ou adequar novas formas de organização e planejamento nas práticas dessas professoras. Alarcão (2005) salienta sobre esse momento reflexivo ao argumentar que

a prática surge como espaço privilegiado de integração de competência, isto só é possível se o professor refletir sistematicamente sobre o que faz e sobre o que vê fazer. A experimentação e reflexão são elementos autoformativos que levam a uma conquista progressiva de autonomia e descoberta de potencialidades. (p. 98) 
Perrenoud (2001) apresenta contribuições a respeito da prática docente ao afirmar que esta pode tornar-se negligente em alguns momentos devido à falta de incentivo e a não promoção de uma formação continuada. Por conseguinte, essa formação faz-se necessária na medida em que tem como objetivo conduzir um espaço de reflexão da ação, além de revitalizar novas técnicas e práticas que surgem para movimentar novamente o cotidiano do professor que passa a conhecer novos horizontes.

O habitus ${ }^{5}$ incorporado por estas professoras tornava suas práticas rotineiras, mecanizadas, sem intencionalidade e perspectivas inovadoras, ou seja, essas práticas faziam parte do habitual, afastando possíveis reflexões acerca do que se estava sendo proposto em sala de aula e com quais finalidades:

No início da carreira [...] o professor em formação inicial ou principiante ainda tenta empregar saberes procedimentais, receitas, técnicas, métodos, modelos. Já nessa etapa contudo, o habitus intervém na operação desses procedimentos e esquemas de ação. Pouco a pouco, a parte das rotinas sob controle da parte menos consciente do habitus vai crescendo. (Perrenoud, 2001, p. 164)

Dessa forma, destaca-se que a formação continuada reafirma-se quando é motivada em um patamar de legislação. Esse tipo de formação é direito dos professores e está assegurado pela lei n. 9.394, de 20 de dezembro de 1996, que estabelece as diretrizes e bases da educação nacional:

Art. 62. A formação de docentes para atuar na educação básica far-se-á em nível superior, em curso de licenciatura plena, admitida, como formação mínima para o exercício do magistério na educação infantil e nos cinco primeiros anos do ensino fundamental, a oferecida em nível médio, na modalidade normal. $\S 1^{\circ}$ A União, o Distrito Federal, os Estados e os Municípios, em regime de colaboração, deverão promover a formação inicial, a continuada e a capacitação dos profissionais de magistério. $\S 2^{\circ} \mathrm{A}$ formação continuada e a capacitação dos profissionais de magistério poderão utilizar recursos e tecnologias de educação a distância. (Brasil, 1996)

Nesse contexto, a intervenção buscou problematizar uma extensão de uma formação continuada pautada no esclarecimento da realidade de uma instituição de referência em educação infantil. Assim, teve como fator norteador a realização de uma visita técnica ao Núcleo de Educação da Infância, junto com 18 professoras do Cemei, com a finalidade de conhecer 0 núcleo, suas instalações e sua dinâmica de funcionamento, propiciando às professoras um momento vivencial a respeito da sua organização administrativa, técnico-pedagógica e de experiências de observação em sala de aula.

${ }^{5}$ Habitus é concebido como esquemas individuais socialmente constituídos e estruturados nas mentes de modo a orientar funções e ações do agir cotidiano.

Regae: Rev. Gest. Aval. Educ. Santa Maria $\quad$ v. 8

ก. 17

Pub. contínua 2019

p. $1-13$ 
O processo de intervenção iniciou-se com um planejamento e ainda no momento de observação foi possível estabelecer horários e dias de acordo com a disponibilidade do grupo de professoras. Nesse momento houve também uma reunião, na qual foram entregues as cópias do texto Currículo em movimento (Rêgo, 1999) que seriam distribuídos pela coordenadora no dia seguinte para todas as professoras com finalidade de fazer com que as mesmas tomassem conhecimento da metodologia adotada pelo NEl.

Passado esse primeiro instante, seguiu-se para o segundo momento da intervenção que aconteceu na Creche Oscarina Torres e que se caracterizou por uma exposição a respeito do funcionamento, história do Núcleo, sua metodologia, rotina e organização das turmas. Houve uma roda de conversa, na qual foram colocadas questões sobre a divisão dos grupos e a coleta dos nomes das professoras para a futura visita ao Núcleo.

Ainda neste dia foi aplicado um questionário de auto-avaliação com as professoras focalizando sua prática didático-pedagógica com o objetivo de constatar o andamento da prática das mesmas. O questionário foi respondido por 13 professoras.

$\mathrm{Na}$ análise do questionário um fator chamou atenção, que foi a resposta à seguinte pergunta: "Você possui uma prática pedagógica definida? Se sim, justifique sua resposta com seus respectivos fundamentos teóricos". Partindo dos resultados obtidos, comprovou-se que as respostas se encaminhavam para uma indefinição de linha norteadora da prática pedagógica, pois não havia um fundamento teórico que justificasse tais práticas. Posto isso, pode-se concluir que a intervenção serviria para conhecer a metodologia tema de pesquisa ${ }^{6}$ utilizada pelo NEl e tomá-la como motivadora e como requisito básico para uma reflexão sobre suas próprias práticas pedagógicas.

$O$ terceiro momento da intervenção ocorreu quando então foi realizada a visita técnica ao Núcleo de Educação da Infância da UFRN em Natal/RN. Ao chegar ao NEI as professoras se direcionaram para o auditório e, posteriormente, houve a recepção e divisão do grupo maior em dois subgrupos. Assim, o primeiro foi encaminhado para observar as salas de aula, sendo o critério de escolha os respectivos níveis aos quais as professoras ensinavam no Cemei. O segundo subgrupo, por sua vez, ficou no auditório para assistir uma palestra que enfatizava a instituição desde a sua estrutura até seu funcionamento e o vínculo com o campus central da Universidade Federal do Rio Grande do Norte. Ao final da palestra também foi aberto um diálogo para as possíveis perguntas e as professoras esclareceram dúvidas, buscando entender sobre a metodologia que 0 núcleo trabalha.

O quarto momento da intervenção ocorreu com a socialização da visita e das observações realizadas durante a viagem. Inicialmente o momento contou com uma dinâmica de balões que deveriam ser estouradas por uma dupla de professoras que não observaram a mesma sala, para que assim, a socialização fosse mais diversa e com elementos de vivências distintas. As duplas estouravam os balões e dentro deles haviam algumas perguntas relacionadas as observações em sala, palestra e outros elementos importantes que seriam respondidos e debatidos por todos que estavam presentes. Buscou-se um aprofundamento na discussão sobre a metodologia do Núcleo de Educação da Infância que se constitui pelo tema de pesquisa, que é definido por Rêgo (1999) como

6 Constitui-se por uma metodologia que articula três eixos: o contexto sociocultural, a estrutura dos conhecimentos de área e os processos de construção de conhecimentos nas crianças.

\begin{tabular}{l|c|c|c|c|}
\hline Regae: Rev. Gest. Aval. Educ. & Santa Maria & v. 8 & n. 17 & Pub. contínua 2019
\end{tabular}

p. $1-13$ 
o tema de pesquisa deve partir da curiosidade das crianças e consequente envolvimento do grupo, onde vai se constituindo em objeto de estudo, à proporção que os questionamentos vão sendo elucidados. Professores e crianças apropriam-se dos conhecimentos das diferentes áreas, à medida que vão em busca de resposta para suas questões. (p. 68)

A exposição e o debate acerca do tema de pesquisa buscou resgatar o entendimento que elas possuíam sobre essa metodologia, esta, por sua vez, adquirida por meio do texto disponibilizado para leitura, da apresentação das estagiárias e também do que foi apresentado na palestra e nas próprias observações do Núcleo de Educação da Infância.

Após a verificação de que as professoras já tinham adquirido uma série de conhecimentos foi proposto que elas colocassem em prática a metodologia do tema de pesquisa, aplicando-a em suas respectivas turmas durante o período de uma semana. Para norteá-las foi entregue um texto elaborado com algumas instruções na qual detalhava-se passo a passo todo o proceder, ou seja, nele explicitavam-se os elementos que iam desde a concepção sobre a criança e a escolha do tema de pesquisa até mesmo o planejamento que deveria ser feito por todas aquelas que desejam desenvolver a proposta.

O quinto momento foi realizado a partir de uma observação do que havia sido proposto, dessa forma, no turno matutino foi observado algumas salas de aula e verificouse que algumas delas já possuíam seu tema de pesquisa, enquanto outras ainda estavam no exercício de descoberta. Uma turma de nível $V$ teve como tema $O$ circo, que foi pensado pelo fato de ter chegado um circo na cidade que despertou o interesse e a curiosidade de todos da sala. A professora procedeu conforme o combinado: escolheu o tema de pesquisa, identificou o que eles sabiam a respeito e o que queriam saber, elaborou seu planejamento e objetivos e realizou algumas atividades.

O sexto e último momento se constituiu pela segunda parte da observação em sala de aula, o nível II foi uma das turmas observadas e teve como tema $O$ piolho. Embora muito pequenos o discorrer das aulas foi um sucesso. A escolha do tema, segundo a professora, foi devido ao fato de que algumas crianças chegavam até a escola negligenciadas por essa higenização capilar, assim, tornava-se retundante o interesse das crianças em discutir tais questões. Ademais também foi construido um cartaz com o que eles sabiam e o que eles queriam saber sobre o piolho e por fim foram realizadas algumas produções expostas nas paredes da referida sala.

\section{Resultados da implantação do projeto de intervenção na perspectiva da formação continuada do professor de educação infantil}

Ao longo das últimas décadas a criança tem sido alvo de uma ressignificação do seu papel dentro da sociedade, isto fez com que algumas políticas públicas no decorrer da história da civilização se voltassem fortemente a este público. Em virtude dessas dimensões os desígnios sociais e governamentais ganharam um novo direcionamento, assim, encaminham-se para a garantia de condições para que as crianças se desenvolvam enquanto cidadãs: 
A partir do momento em que alcançou-se uma consciência sobre a importância das experiências da primeira infância, foram criadas várias políticas e programas que visassem promover e ampliar as condições necessárias para o exercício da cidadania das crianças, que por sua vez, passaram a ocupar lugar de destaque na sociedade. (Caldeira, 2010, p. 5)

À vista disso, destaca-se a relevância da contínua formação do professor neste campo, justificado pela necessidade do docente em se adequar e aprimorar seus conhecimentos tendo em mente oferecer seu melhor enquanto profissional da educação. Além disso, despertar-se para o compartilhamento de ideias e, consequentemente, revitalização do laço com seus colegas de trabalho.

Nesse contexto, recorreu-se a uma formação continuada com as professoras da educação infantil da instituição Oscarina Torres, visando a criar oportunidades de parcerias entre coordenação e corpo docente. Outrossim, buscou-se conduzir ao aperfeiçoamento e reflexão sobre a prática dessas professoras, de modo a instiga-las a buscarem estudar e melhorar cada vez mais sua atuação em sala, haja vista que, essa procura pela melhoria das práticas docentes atinge diretamente o público alvo que são as crianças.

Estes estudantes, por sua vez, estão se encaminhando para cidadania, logo, cabe ao professor formar pessoas dentro das concepções existentes. Nessa perspectiva, além de conteúdos deve-se repassar valores e buscar desenvolver habilidades no aluno tendo em vista o seu uso social.

A formação continuada, portanto, possui em sua essência um elemento mobilizador que é o aluno, é ele o motivo central pelo qual o docente se encontra em sala de aula, então é por ele que se deve buscar a mudança e o aperfeiçoamento, pois "o aluno é um dos agentes mobilizadores da mudança do professor" (Orsolon, 2001, p. 24).

Ao trabalhar com o tema de pesquisa as professoras adquiriram uma experiência importante que só veio a acrescentar em suas práticas. Para isso foi necessário o envolvimento da coordenação e dos colegas de trabalho, a presença destes nas reuniões, para efeito de compartilhamento e a socialização das suas experiências e ideias para a construção de um ambiente democrático e mobilizador. Essa parceria é primordial pois "O trabalho de parceria, que se constrói articuladamente entre professoras e coordenação, possibilita tomada de decisões capazes de garantir o alcance das metas e a efetividade do processo para alcança-las" (Orsolon, 2001, 25).

Além dessas contribuições é possível assinalar que ao adentrar-se em uma nova realidade escolar e de prática docente, as professoras acabaram adquirindo um acervo de competências e habilidades que, se não fosse pela promoção de uma formação continuada, elas não as teriam, logo, resultar-se-ia no reduzido número de possibilidades, inovações, vivências.

Nesse sentido, as professoras do Cemei obtiveram uma experiência de certa forma acelerada em decorrência do curto espaço de tempo das atividades desenvolvidas. Outro elemento a ser destacado seria que os alunos que geralmente integram-se a essa metodologia, como acontece no NEl, estão submetidos a ela desde muito pequenos, à vista disso, possuem uma familiaridade e uma adaptação assegurada, diferentemente dos alunos da Creche Oscarina Torres, ao qual tiveram o seu primeiro contato. 
Apesar de alguns empecilhos foi perceptível que nesse período as professoras se engajaram e foram em busca de atingir o objetivo final da experiência. De modo que isso favoreceu tanto o professorado quanto também as crianças que foram instigadas a desenvolverem certas condições e habilidades que antes não eram requeridas.

Em suma, a experiência de intervenção teve como resultado proporcionar um momento motivacional da prática docente dentro de uma perspectiva macro, ou seja, almejou-se instigar a ação-reflexão-ação do professor sobre sua prática cotidiana e, ao mesmo tempo estreitar laços e promover parcerias com toda a escola e, principalmente, com a coordenação.

\section{Considerações finais}

Ao iniciar este trabalho, partiu-se da necessidade de discorrer a respeito da formação continuada como parte significativa de um estágio realizado pelo curso de pedagogia da UFRN/Ceres/Caicó. Para isso foi necessário se trilhar um caminho que envolveu uma compreensão acerca desse aspecto formativo, a caracterização da escola, observações e também um projeto de intervenção. Por conseguinte, elencou-se tais experiências com os saberes teóricos, reforçando assim a indissociabilidade entre teoria e prática.

Diante desse cenário realizou-se a pesquisa na Creche Municipal Dona Oscarina de Oliveira Torres e a partir dos dados empíricos abordados, tanto nas observações como também nas formações com o corpo docente, tornou-se perceptível a necessidade de se trabalhar com o tema formação continuada e organização do trabalho docente, realizando assim uma viagem ao Núcleo de Educação da Infância para que fossem observadas as práticas das professoras e a metodologia do tema de pesquisa. Além disso, outras atividades de formação ainda foram implementadas e contribuíram satisfatoriamente para as práticas das professoras na Educação Infantil.

Sendo assim, pode-se verificar que o corpo docente e a coordenação pedagógica participaram de forma autônoma na realização da pesquisa. Além disso, a partir do projeto de intervenção alteraram-se algumas concepções acerca de suas práticas escolares, dentre estas destacam-se a contribuição para uma experiência com o tema de pesquisa nas suas respectivas salas de aula, o início de uma rotina com roda inicial e final e ainda uma maior consideração pelo interesse dos alunos em relação aos assuntos estudados.

\section{Referências}

ALARCÃO, Isabel (coord.). Formação reflexiva de professores: estratégias de supervisão. Porto: Porto, 2005.

BRASIL. Lei de diretrizes e bases da educação nacional. Brasília: MEC, 1996.

BRASIL. Resolução CNE/CEB n. 5/2009: diretrizes curriculares nacionais para a educação infantil: Brasília: CNE, 2009.

BRASIL. Estatuto da criança e do adolescente. Rio de Janeiro: Imprensa Oficial, 2002.

BRASIL. Parâmetros básicos de infra-estrutura para instituições de educação infantil: Brasília: MEC, 2006. 
BRASIL. Parâmetros nacionais de qualidade para a educação infantil. Brasília: MEC/SEB, 2006b.

BETTELHEIM, Bruno. A psicanálise dos contos de fada. São Paulo: Paz e terra, 2002.

CALDEIRA, Bianca Laura. O conceito de infância no decorrer da história. Curitiba: Secretaria da Educação do Paraná, 2010. Disponível em http://www.educadores.diaadia.pr.gov.br/arquivos/File/2010/artigos teses/Pedagogia/o co nceito de infancia no decorrer da historia.pdf. Acesso em 16 nov. 2018.

GIL, Antônio Carlos. Métodos e técnicas em pesquisa social. São Paulo: Atlas, 1999.

IMBERNÓN, Francisco. Formação docente e profissional: formar-se para a mudança e a incerteza. São Paulo: Cortez, 2010.

LIBÂNEO, José Carlos; OLIVEIRA, João Ferreira de; TOSCHI, Mirza Seabra. Educação escolar: políticas, estrutura e organização. São Paulo: Cortez, 2013.

MACKEY, Letícia; REGANHAM, Simone Gonçalves. A importância da educação infantil no processo de escolarização. Revistas das Faculdades Integradas Claretianas, Rio Claro, n. 2, 2009, p. 58-70.

ORSOLON, Luiza Angelina Marino. O coordenador/formador como um dos agentes de transformação da/na escola. In: ALMEIDA, Laurinda Ramalho de; PLACCO, Vera Maria Nigro de Souza (orgs.). O coordenador pedagógico e o espaço de mudança. São Paulo: Loyola, 2001, p. 25-40.

PERRENOUD, Philippe. Formando professores profissionais: três conjuntos de questões. In: PAQUAY, Léopold; ALTET, Marguerite; CHARLIER, Évelyne; PERRENOUD, Philippe, (orgs.). Formando professores profissionais: quais estratégias? Quais competências. Porto Alegre: Artmed, 2001, p. 11-22.

REGO, Maria Carmem F. D. O currículo em movimento. Caderno Faça e Conte, Natal, v. 2, n. 2, 1999, p. 61-82.

SILVA, Ana Maria; OLIVEIRA, Marta Regina Furlan de. A relevância da formação continuada do professor de educação infantil para uma prática reflexiva. JORNADA DE DIDÁTICA: DESAFIOS PARA A DOCÊNCIA E SEMINÁRIO DE PESQUISA DO CEMAD, 3, 2014. Anais ... Londrina: UEL, 2014.

TRIVINÕS, Augusto Nibaldo Silva. Introdução à pesquisa em ciências sociais: a pesquisa qualitativa em educação. São Paulo: Atlas, 1987.

Nathany Morais de Souza é estudante do curso de Pedagogia da Universidade Federal do Rio Grande do Norte.

Endereço: Rua José Evangelista, 391 - 59315-000 - Ipueira - RN - Brasil.

Orcid: https://orcid.org/0000-0002-0213-3670.

E-mail: nathany.morais@hotmail.com.

Micarla Silva de Azevedo é estudante do curso de Pedagogia da Universidade Federal do Rio Grande do Norte.

Endereço: Rua Severino Elias Pereira, 120 - 59360-000 - Parelhas - RN - Brasil.

Orcid: https://orcid.org/0000-0002-6585-8353.

E-mail: silvamicarla14@gmail.com. 
Flavia Alessandra Pereira Galdino é estudante no curso de Pedagogia da Universidade Federal do Rio Grande do Norte.

Endereço: Rua Alcindo Lopes Vasconcelos, 51 - 59380-000 - Currais Novos - RN Brasil.

Orcid: https://orcid.org/0000-0002-3587-6411.

E-mail: flaviagermanotta@gmail.com.

Nazineide Brito é doutora em Educação pela Universidade Federal do Rio Grande do Norte.

Endereço: Rua Generina Vale, 1056 - 59300-000 - Caicó - RN - Brasil.

Orcid: https://orcid.org/0000-0002-6749-0951.

E-mail: nazibrito@gmail.com.

Recebido em 4 de julho de 2019.

Aprovado em 26 de agosto de 2019.

(c) (i) 